\title{
Surgery during the peninsular wars
}

\begin{abstract}
The study "Surgery during the Peninsular Wars" results from an investigation focused on the surgical procedures in the Anglo-Luso Army. We will show a multitude of surgical procedures and the great challenges presented to the surgeons in the first contacts with the war wounded. We report the work of surgeons at the front lines and in field hospitals and the controversies about the techniques of incision of fragile limb tissues before initiating the surgery and about the exact moment of amputation after injury.

"Being able to give tranquillity and comfort to a heroic and victorious soldier allows the most sublime pleasure that the human mind can feel" Robert Jackson (Physician)"
\end{abstract}

Volume 3 Issue 6 - 2018

\section{José Luiz Assis \\ University IHC-UN CEHFCi-UE, Portugal}

Correspondence: José Luiz Assis, University IHC-UN CEHFCi-UE, Rua da Sociedade, Lote I5-n 278 I $2200-155$ Abrantes, Portugal, Email josalassis@gmail.com

Received: September 07, 2018 | Published: November 27 2018

Keywords: medicine, surgery, medical personalities, armies, war

\section{Introduction}

This study opens several research perspectives: the field of Military Medicine, Military Surgery, the history of diseases, therapy, physician and surgeon's relations with the patient, medical and sick mindset, the importance of medicine in the mentality of the great military leaders, the reforms of armies, medical hospital administration, medical logistics, the relationship between Physician Major and Surgeon Major, academic contacts between surgeons of enemy armies in times of war and during interruptions in the campaigns, the cooperative relationships between physician and surgeon during the campaign, the decisive importance of health services in the outcome of the victory of the Anglo-Portuguese Army over the Napoleonic eagles.

\section{Medical and surgical practices in the peninsular wars}

In the eighteenth century, surgery managed to acquire considerable technical development, especially at the level of Anatomy. It was thanks to the studies of the excellent anatomist, physiologist and English surgeon John Hunter (1728-1793) that in the nineteenth century surgeons began to understand that surgical practice should be based on Anatomy and the results of Experimental Medicine and not on empirical data as usual until then. This change of mentality led to consider the surgeon as a prestigious technician. ${ }^{1}$ During the Napoleonic Wars, as in those that occurred before and after, the success of military campaigns depended on the good state of health in which the armies were found. We can say that their excellent health was more important than many of the other requirements. New surgeons, when they first contacted the war-wounded, had much to learn with no time at all. Their greatest difficulties were related to the lack of preparation to face the great number of wounded and injured resulting from the battles. It was to fill this lack of preparation that James McGrigor (1771-1858), ${ }^{2}$ Inspector General of Hospitals, after assuming office in January 1812 , ordered that new surgeons and surgeon helpers recently arrived in the Army from surgery schools or from the Hospital Real

${ }^{1}$ Fresquet LJ. Signo, enfermedad, amputatión de Larrey. Valência: written text; p. 2.

${ }^{2}$ For further study, please consult: Sir James McGrigor. The Scalpel and Sword, the Autobiography of the Father of Army Medicine. Scottish: Scottish Cultural Press; 2001. de Todos-os-Santos and the Hospital Real de São José in Lisbon ${ }^{3}$ were first placed in the Military Medicine Institution in Lisbon before being incorporated into the regiments. ${ }^{4}$ During the Peninsular Campaigns, first under the command of William Carr Beresford (1768-1854) and then under Arthur Colley Wellesley, duke of Wellington (1769-1852), Marshal of the Anglo-Portuguese Army, the Medical Staff received regular reports and, according to these reports, sought to provide the necessary support to any surgeon.

The promotion of assistant to regiment surgeon to official assistant surgeon, or even from this to surgeon of the regiment, was made from the reputation acquired in the treatment of wounded in campaign or by performing exams in Lisbon. In combat, the surgeon and his two surgeon aides positioned themselves immediately behind the army unit, while the other surgeon helpers were shifted to the front with medicines and medical instruments. In the Peninsular Campaigns, amputations, trepanations and wound exploration were considered the most important surgeries. In the front lines, the work of surgeon helpers consisted in providing first aid and transport of the wounded to the regiment hospitals located in the rear. In the regiment hospitals their tasks consisted in disinfections, application of compresses, extracting bullets, placement of splints and closure of wounds. In field hospitals, more difficult surgeries such as amputations and wound exploration were performed and the oldest and most experienced surgeons were who, within their surgical knowledge, made the most appropriate decisions.

One of the great challenges for the medical services in the Peninsular Campaigns was the amount of injuries caused due to combat. Many of them eventually died of late or inadequate evacuation ${ }^{5}$ and often because of difficulties in getting to a field hospital. ${ }^{6}$ The casualties travelled on foot, often aided by comrades in arms, on mules or carts, or died slowly in the fields at the mercy of robbery, murder and death

\footnotetext{
${ }^{3}$ Silva P. Anotações sobre a História do Ensino da Medicina em Lisboa. desde a criação da Universidade Portuguesa Série III. 2002;7(5):237-249.

${ }^{4}$ Winstanley J. Wellington's Field Surgeons. London: Churchil Clinic, UK: Written text; 2005. $206 \mathrm{p}$.

${ }^{5}$ Crumplin MKH. The Management of Pain and Transport of the Sick and Wounded in the Napoleonic Wars. (1793-1815). Edinburgh: Written text; 2005. $7 \mathrm{p}$. ${ }^{6} \mathrm{Ibid}$.
} 
by gun fire or dehydration. ${ }^{7}$ The number of wounded soldiers with large scalp cuts was quite significant, (Figure 1). Cavalry units caused this kind of injury when they struck the blows with their sabres from top to bottom with a considerable force during Infantry charges. These were commonplace, mutilating, and sometimes deadly. The multiple blows could be small and superficial, but also large and deep, fracturing the skull reaching the brain. He was patient with $\mathrm{Mr}$. Collier. On the 5 th day after the injury, a trepanation was performed.

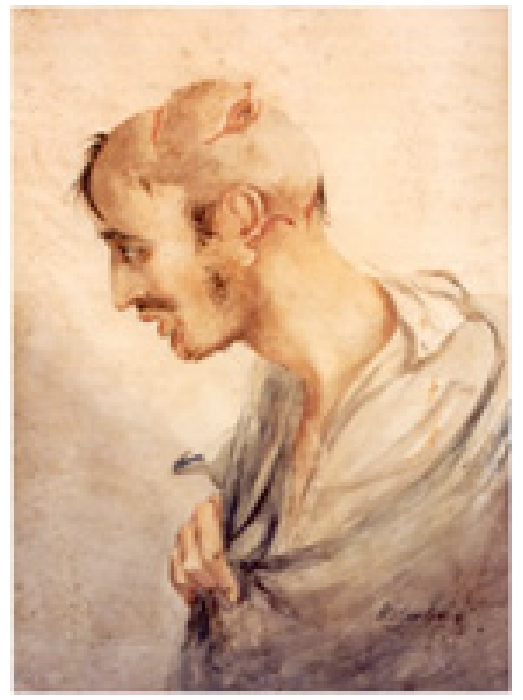

Figure I Soldier of the I ${ }^{\text {st }}$ Royal Dragoons wounded in the skull by multiple blows of sabre. The Paintings and Sketches of Sir Charles Bell (I809-1815), Edinburgh, Royal College of Surgeons.

Other weapons, of great piercing power, were the spear and the spontoon, used by the French Heavy Cavalry. Soldiers, even with helmets, were not guaranteed protection. Some of the men remained alive for a few days after being wounded by those weapons and the infection could be generalized, leading to sepsis and would eventually death without any treatment (Figure 2 ) ${ }^{8}$ In addition to these very common injuries, there were others caused by the mechanisms of firearms and burns. Low-velocity bullets with little force, housed in the head, constituted a simple surgical situation. Sometimes the surgeon made a small incision on the scalp and removed the projectile. There were many survivors of this type of injury. The most complex cases were those caused by the impact of bullets on the head reaching the brain, which were fatal and caused infection, causing edema and sometimes protrusion. Symptoms of cerebral compression were easily identifiable, and although the blood clot and pus were drained successfully, the damage done was irreparable. An example of this situation can be found in Sir James Charles Bell (1774- 1842)

\section{${ }^{7}$ Ibid}

${ }^{8}$ At the Royal College of Surgeons of Edinburgh we can find a skull with eleven blows struck by a sword. The multiple wounds caused in this situation could be superficial, but they could also cause.

${ }^{9} \mathrm{He}$ was born in Fountain bridge, Edinburgh in November 1774 and died in April 1842 at Hallow Park Worchester. Studied Medicine in Edinburgh where he obtained the rank of physician in 1799 , being admitted to the Royal College of Surgeons of Edinburgh that same year. He was Professor of Anatomy and Surgery at the Royal College of Surgeons of London, becoming Regent of Physiology and Surgery at the University of London in (1824). From his vast bibliography we can see: "A System of Dissections Explaining the Anatomy of the Human Body (...)", 2 vols. Edinburgh, 1798; "The Anatomy of the Human Body," 3rd vol., Edinburgh, 1804; "Anatomy of Expression", London, s. d.; lithographs of a soldier who fought at the Battle of Waterloo and died of fungus cerebri six days after being seen by that surgeon. In these situations, the recommended surgery consisted in the extraction of the bone fragments that allowed a better access to clean the injured part.

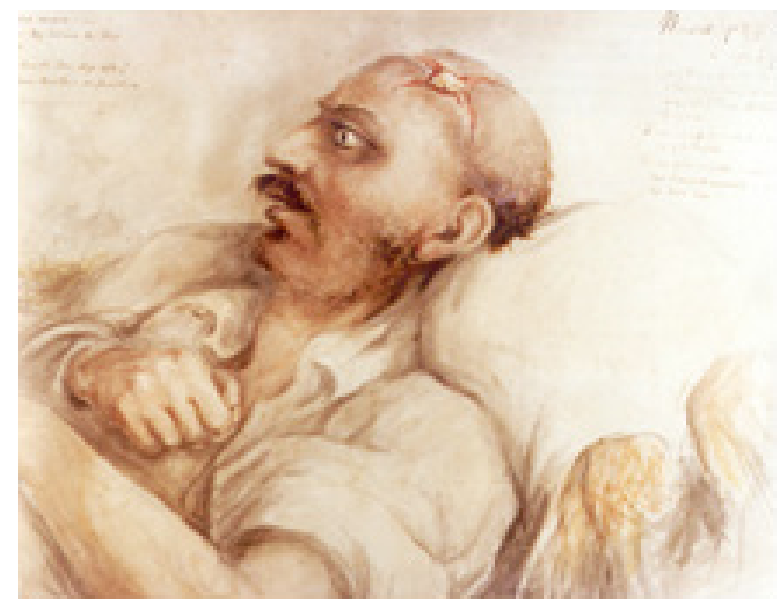

Figure 2 Soldier Wanstell, belonged to the $17^{\text {th }}$ Regiment of Foot. He was wounded in the head by a shotgun bullet.

Upper limb injuries were a major concern for surgeons. When this happened, the surgeon placed his finger on the wound as if it were a probe. If the humerus was fractured, the surgeon would only treat it if his finger would not pass through it, otherwise an amputation would be performed (Figure 3). Another major concern for surgeons was closed chest trauma, that could cause lethal asphyxia, and surgical practice often consisted of emptying the pleural cavity of air, fluids, or blood (Figure 4). In the Peninsular Campaigns, Guthrie was the first surgeon to practice the closure of penetrating wounds..$^{10}$ After this, other surgeons started performing this procedure. This surgical practice allowed to save some wounded since it avoided pneumotorax and hemorrhage. ${ }^{11}$ The soldiers wore a breastplate made of buffalo skin that protected them from side shots and sabre blows. Many shots in the chest and abdomen, while not injuring the skin, could be equally devastating as the projectile's force had a strong impact on the internal body structures of the body. Abdominal surgery was characterized by a superficial practice since there was no availability for surgeons were not able to perform adequate incisions in the abdomen, with relaxed muscles, in a quiet and painless patient. Anastomoses were not practiced, although there were experimental works performed successfully on dogs. ${ }^{12}$ Intra-abdominal surgery at war would only definitively establish itself in our century during the First World War. When the projectile penetrated the abdomen and damaged the intestines or solid organs, such as the liver, the patient's recovery depended largely on his ability to cope with the bleeding. In such a situation, the survival of the patient depended on their resistance while attempting to prevent sepsis and surviving the initial lesion. ${ }^{13}$ Sometimes it happened that the wounded could recover. ${ }^{14}$ If there was intestinal protrusion with the intestine intact, the surgeon placed the

"New Idea of the Anatomy of the Brain," London, 1811; "The Nervous System of the Human Body", London, 1830.

${ }^{10}$ Crumplin Michael KH. Wellington's Combat Surgeon, George James Guthrie. Edinburgh: Written text; 2006. p. 4.

${ }^{11}$ Ibid.

${ }^{12}$ Idid. Napoleonic Wars, Surgical History, Military Surgery, Larrey, Guthrie, McGrigor. Edinburgh: Written texto. 2002. 25 p.

${ }^{13}$ Ibid

${ }^{14} \mathrm{Ibid}$. 
soldier in a position that allowed the abdominal muscles to relax and then placed the intestine into the abdominal cavity (Figure 5).

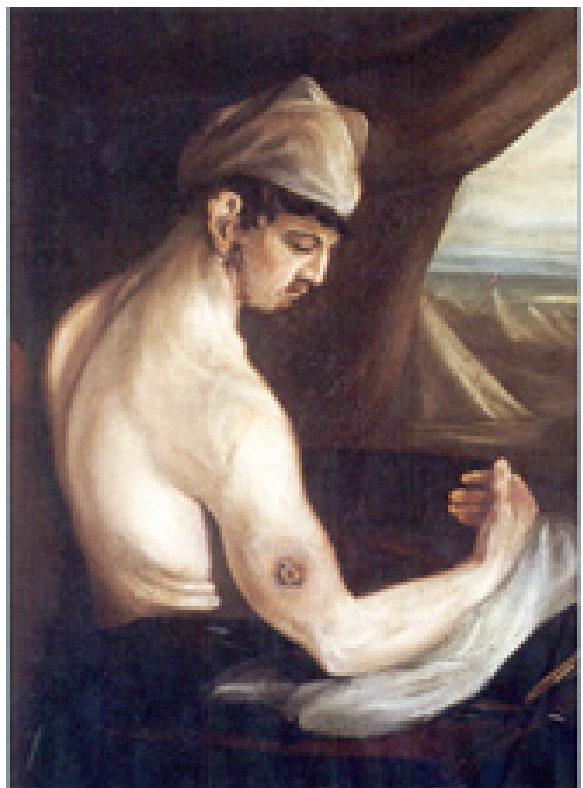

Figure 3 The Paintings and Sketches of Sir Charles Bell (1809-1815), Edinburgh, Royal College of Surgeons.

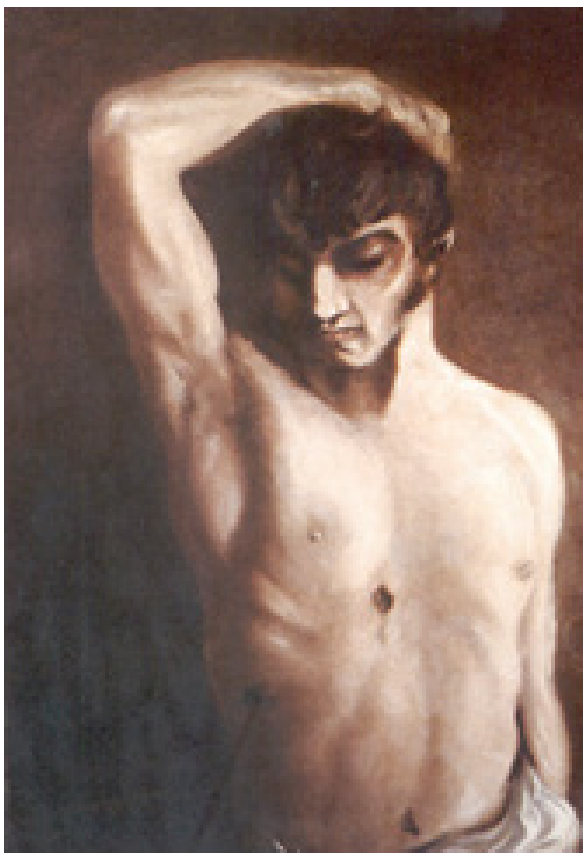

Figure 4 Sick with wounds caused by the entrance and exit of a shotgun bullet. The projectile entered the seventh right rib without reaching the vital organs. The Paintings and Sketches of Sir Charles Bell (1809-18I5), Edinburgh, Royal College of Surgeons.

When the bowel was injured, some surgeons sought to externalize the intestinal wound by attaching it to the skin. If the intestine was severely damaged or gangrenous, the surgeon would remove the dead tissues and eventually construct an artificial anus, sewing the intestine to the skin to prevent contamination of the peritoneal cavity (colostomy). Abdominal injuries were treated by surgeons with very little hope of recovery of the patient given the difficulties that existed in the treatment of this type of injuries. Thigh injuries, usually worsened by a femoral fracture or neurovascular injury, located near the perineum was a major concern for all surgeons, even for the most experienced, since it was very difficult to treat, (Figure 6). Round 6, 8, 9 and $12 \mathrm{lbs}$ projectiles, low-velocity canister shot or musket bullets, rifles, or pistol bullets were responsible for many of the wounds of war. There were, in fact, numerous, complex and contaminated wounds that surgeons had to deal with.

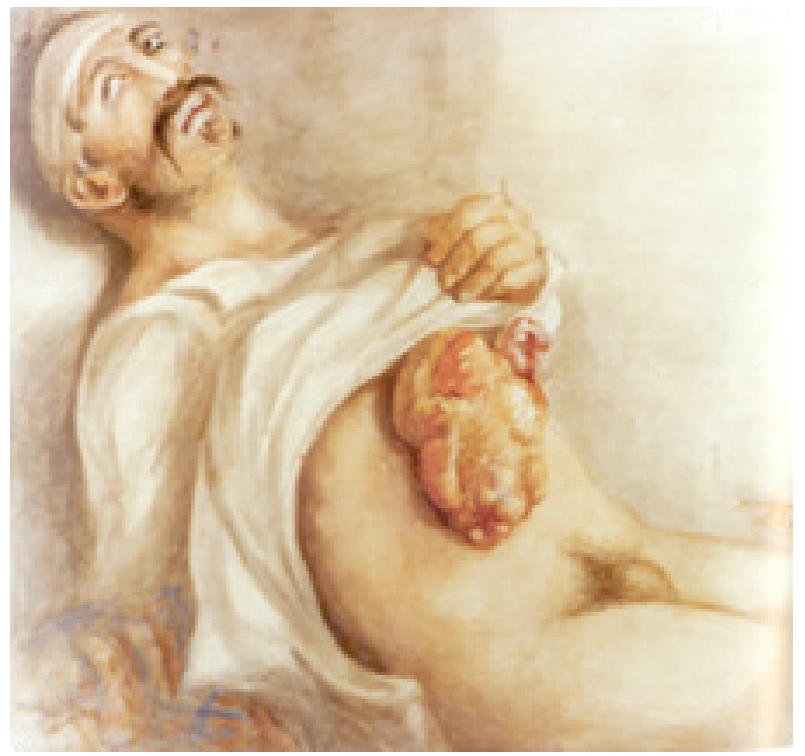

Figure 5 Soldier Peltier of the $3^{\text {rd }}$ French Lancers wounded by a blow of sabre in the abdomen. The Paintings and Sketches of Sir Charles Bell (1809-1815), Edinburgh, Royal College of Surgeons.

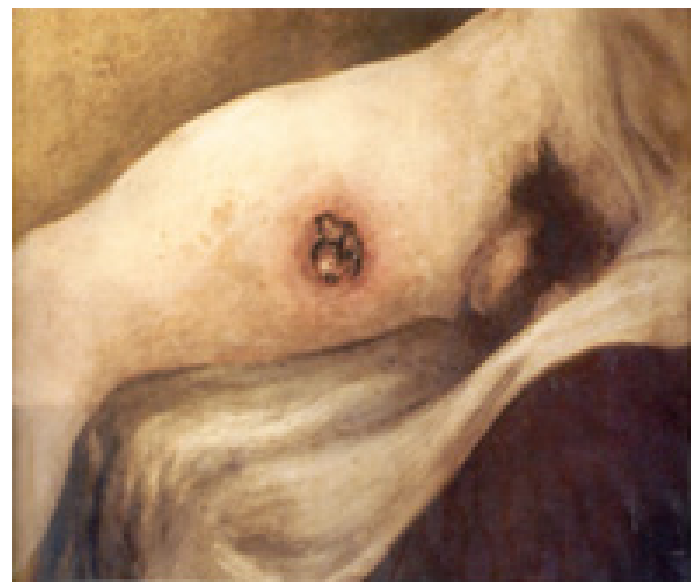

Figure 6 Soldier Rifleman Chambers of the 95th Regiment with right femur injury caused by a shotgun shot. The Paintings and Sketches of Sir Charles Bell (1809-1815), Edinburgh, Royal College of Surgeons.

Amputation was considered the most important surgical procedure since it consisted in removing the painful and injured part of the tissues while trying to prevent haemorrhaging and sepsis. This was the most serious surgical procedure practiced in health services by military surgeons. If the surgeons needed to amputate one of the limbs, the patients would be positioned according to the circumstances, the 
place of the surgical practice, the supports, the nature of the lesions and their anatomical location, always playing with the time factor. In most limb amputations, patients eventually fainted. This would let the surgeons work under less pressure since the patients would not feel the pain caused by tissue cuts. Patients were aware that when they had to undergo amputation surgeries of a limb they would have a few minutes of great distress followed by several weeks of discomfort. Although the recovery would very frequently be worsened by sepsis and death, some patients managed to recover successfully. The wounded knew that subjecting themselves to the risk of surgery could bring those advantages: they could survive.

Medical indications for ablation of a limb were very clear, it should occur when the surgeon was in the presence of gangrene, rupture of the joint or complicated fracture. There was a consensus regarding its execution, although there were some disagreements about the exact moment in which it should be executed. French surgeons argued that surgery should take place shortly after the injury if the chances of saving the limb were reduced. They were more conservative than Anglo-Portuguese army surgeons with whom amputations, especially those performed to the upper limbs, would have been done indiscriminately. ${ }^{15}$ There was little knowledge about postoperative complications, particularly sepsis, lack of bone alignment or even pain caused by amputation. At that time there was great controversy over the incision technique in the fragile limb tissues to initiate amputation. Older and experienced surgeons in military campaigns argued that the most appropriate method was circular or guillotine, since it was quick, easy and had the advantage of leaving the wound open. They would split the skin and apply a circular incision with rapid movements, followed by cutting the muscles. The soft tissues were retracted with a retractor of leather tissues or by compresses and the bone was sawn with a saw. The arteries were clamped. The veins were carefully separated from the muscle and then lacquered with line. The tourniquet, which had previously been applied to minimize blood loss during surgery, was relieved while the surgeon proceeded to assess the condition of the stump's surface to restrain bleeding points. The edges of the wounds were sutured using linen and silk. It was the surgeon's main concern to reduce haemorrhaging and pain exposure time as best he could. Surgery practiced in such a situation required surgeons to have a calm and cool but effective attitude. Most of the amputations lasted about twenty to thirty minutes, yet Baron Dominique Jean Larrey (1766-1842) took three to four minutes to amputate a member. ${ }^{16}$

${ }^{15}$ The Battle of Talavera on July 28, 1809, is considered the most violent of the Peninsular War, the number of casualties on the side of the Allied Army was 5363. When all the wounded were already collected in the convent of Deleitosa near Troxillo, Guthrie was very shocked with the indiscriminate amputations that were practiced to the superior members and made a formal complaint to his superiors to give them account of the situation, because of these grievances he would gain many enemies. Guthrie was very reluctant to carry out the amputations and only practiced them in extreme cases. At the Battle of Albuera on May 17, 1811, Dr Stamford requested permission from Guthrie to amputate the thigh of a soldier who had been wounded by a bullet. Guthrie declined the request applied a club to the soldier's thigh and ordered Dr. Samford to return to his regiment. Cf., Idem., Ibid., P. 4 and John Winstanley, Wellington's Field Surgeons, London, Churchill Clinic, UK, p. 203.

${ }^{16}$ Crumplin Michael KH. A Hight Price for Victory, The Management of pain and Transport of the sick and Wounded in the Napoleonic Wars, (1793-1815). Edinburgh: Texto Policopido; $5 \mathrm{p}$.
Descriptions of surgical victims of the Napoleonic Wars tell us that the most painful moment in an amputation surgery was the cutting of the skin and the section of nerves and arteries. When the surgical act did not go as planned, the discomfort was total. Nursing care would be minimal and usually performed by fellow soldiers, women and clergymen who accompanied the campaigns. During the Campaigns there was no policy of administering painkillers or anaesthetics ${ }^{17}$ on the instructions for military surgeons. ${ }^{18}$ Alcohol was more commonly used as an anxiolytic to control the patient's anxiety than as an analgesic. The surgeons in service of the navy used Rum, while the ones in the army administered Rum, port wine, Brandy or even Gin, depending on the region where the military campaigns were being carried out. After the surgeries only a cordial drink (a mixture of a spirit drink with water or other liquid) was dispensed, when the surgeon understood that it was necessary to revive the patient. It was very difficult to follow the practice of prescription and regular administration of analgesics because, on the one hand, there was no importance attached to the subject and, on the other, there were no records of prescriptions on which surgeons could rely.

In 1813, the surgeon John Hennen (1779-1828) in Bilbao administered about three to four grains of opium. The existing regulation for regiment hospitals provided that for a herd of 250 men there should be eight ounces of opium tincture and three ounces of pure opium. The drug was administered orally and it was very rarely placed in the bandages for the treatment of painful ulcers and burns. Without any medical prescription designed to reduce the suffering and pain of patients, the greatest contribution that surgeons could make to alleviate pain and suffering would be the speed and timing of surgery. Surgeons underwent surgery as soon as possible, before the limb was swollen or sepsis settled..$^{19}$ Mortality provoked by amputations depended on the ability and experience of the surgeon, on the moment the patient was placed in the surgeon's care, where the wound was located and its severity (Figure 7). With all these constraints to which they were subjected to, morbidity and mortality rates in the campaign were high. These rates were between $10 \%$ and $30 \%$ in the case of primary amputations when performed by an experienced surgeon in a healthy soldier. ${ }^{20}$

Debriding the wounds was a frequent surgical procedure and often difficult if the projectiles were too deep and if the edges of the wound were contaminated. Inside the body its recovery was done by finger palpation. If the surgeon did not feel the projectile through palpation, it would be carefully removed by forceps. In the case of a bone lesion with fragments, they were removed with surgical instruments. In these situations, sometimes infected fragments or other foreign bodies were not detected, either by the surgeon's finger or even

\footnotetext{
${ }^{17}$ Idid., p. 1

${ }^{18}$ Later, in the Crimean Wars between 1854 and 1855 and after the American Civil War, a large number of surgeons when administering the ether and chloroform were very nervous and insecure. Although in the Crimean War amputations had occurred under the advent of General Anaesthesia, there was no great difference in mortality caused by the amputations practiced in the Napoleonic Wars and the Crimean Wars. Cf., Idem., Ibid., p. 1

${ }^{19}$ The first use of anaesthesia was to take place in 1846 at the theater of operations at Massachusetts General Hospital and was given by Professor John Warren and Dr. William Norton to the patient Mr. Gilbert Abbort to extract a small tumor.

${ }^{20}$ Idid. 2002. 20 p.
} 
by the use of forceps, which constituted a serious risk of infection for the patient. Most of the superficial wounds were cleaned and disinfected, but it sometimes happened that the surgeons later could not close those wounds because of tissue edema (Figure 7). During the treatment of wounds surgeons applied bandages and ligatures after sutures. Treatment of fractures was rudimentary; fractured bones were immobilized through the use of linen bands and the patient would have to be immobilized for many weeks in the position of maximum muscle relaxation.

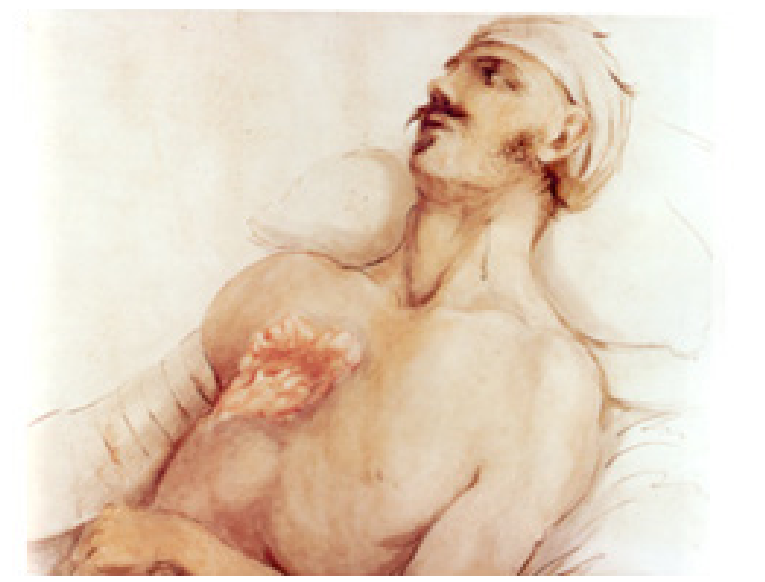

Figure 7 Albrecht Heifer of the King's German Legion. He was wounded in the chest by a cannonball. It did not fracture the ribs but it hurt the lungs. The Paintings and Sketches of Sir Charles Bell (1809-1815), Edinburgh, Royal College of Surgeons.

Surgeons used bandages, ribbons and needles and the suture lines were made of linen or silk when treating these fractures. With more or less suffering in treatment, healing usually took place, but the consequence was inevitably non-alignment of the bone, sometimes with shortening of the limb. Osteomyelitis was a real complication, as it frequently caused fistulas of expulsion of fragments, crises of fever and breakdown of the general state. Although surgery techniques were rude and limited but quickly performed, many lives were saved because of the patient's resistance and sometimes due to luck. We cannot forget the innovation introduced by Georges James Guthrie (1774-1842) in 1813, which consisted in the use of splints "the long splints" applied to fractures of the femur, whose main purpose was to prevent deformations resulting from fractures that obviously caused a change in gait. Anti-inflammatory procedures such as bleeding, purging, and vomiting were ineffective and often severe for the patient. Bloodletting as practiced by surgeons at the service of allied forces was considered the most difficult therapy to understand. Making the patient bleed to syncope (fainting) was to give the surgeon some hope and reduce the patient's discomfort and distress. Bloodletting could be performed at the locale of injury or disease or, generally, at the elbow, in the bloodletting region or leg. This procedure was intended to reduce blood circulation to the patient with wounds or already with sepsis. A patient with a symptomatology characterized by tachycardia, fever and sepsis would be correctly diagnosed by the surgeons as having a serious health problem. As the domain of bacteriology was not yet known, the pathophysiological reactions to sepsis were understood as causal factors of the disease, which implied that it had to be controlled so that the patient would survive. Thus, he would often bleed 20/30 ounces of blood at a time. The techniques varied: cutting the skin, using leeches and scarification. Vascular lesions were imminent, from infection to excessive blood loss and resulting anaemia. Different blades and lancets were used. A tin cup of calibrated brass or a cup of sangria was pressed against the elbow and collected the blood. In addition to this procedure, leeches were also used by physicians and surgeons who carried them in tin cups or boxes to perform bloodletting. To decongest patients or part of their body, twenty or thirty were applied in the appropriate zones. With this study on Surgery in the Peninsular Wars we tried to make an evaluation of what was its practice at the service of the Anglo-Portuguese Army, as well as its contribution to the progress and development of Surgery.

\section{Conclusion}

Surgery in the Peninsular Wars is a study of the surgical practices carried out during the troubled period of the Napoleonic "storm" still poorly known to the general public and the scientific community. We intend, first of all, to highlight the degree of innovation as an area of investigation and historical reflection in the field of Medical History and secondly the primary role it played in the treatment of wounded. Surgeons, while applying many of their innovative surgical practices, were able to solve or at least simplify clinical situations such as the case of femoral artery interruption through placing a finger on the cavity and stopping the flow of blood from breast injuries which were first used in the Napoleonic Wars. Surgical practice has shown marked limitations, particularly in terms of serious injuries to the skull, chest, thigh and abdomen where the wounded were often left to their own devices. Even with all those limitations and without the discovery of anaesthesia and antisepsis, surgical practice was improved. Despite the precarious working conditions, these men acquired knowledge which allowed them to give a remarkable service. They were able to stop bleeding, drain pus from wounds, remove dead tissue and support those on the verge of death. This service is even more remarkable since there was no policy of administering analgesics and anaesthetics. No attention was paid to the matter nor were there any records of prescriptions upon which military surgeons ${ }^{21}$ could rely. In the field hospitals, the main problems that the wounded could find were related to situations of great noise, desperate crowds, lack of water, lack of relief for pain and a comfortable place where they could convalesce. We found a great capacity of resistance of the soldiers to the wounds inflicted on the battlefields that only have justification in the physical robustness and the arduous manual works to which they were used to in the rural environments from where they were coming; they did not expect pain relief and resignedly accepted death if they did not overcome the multiple complications arising from their injuries.

\section{Acknowledgments}

None.

\section{Conflicts of interest}

Author declares that there is no conflicts of interest.

${ }^{21}$ Later, in the Crimean Wars between 1854 and 1855 and after the American Civil War, a large number of surgeons when administering the ether and chloroform were very nervous and insecure. Although in the Crimean War amputations had occurred under the advent of General Anaesthesia, there was no great difference in mortality caused by the amputations practiced in the Napoleonic Wars and the Crimean Wars. Cf., Idem., Ibid., p. 1 